\title{
Saberes pesqueiros relacionados à coleta de siris e caranguejos (Decapoda: Brachyura) no município de Conde, Estado da Bahia
}

\author{
Henrique Fernandes de Magalhães ${ }^{1,4}$, Eraldo Medeiros Costa Neto ${ }^{2}$ \& Alexandre Schiavetti ${ }^{3}$ \\ 'Programa de Pós-Graduação em Zoologia, Universidade Estadual de Santa Cruz - UESC, Campus Soane \\ Nazaré de Andrade, Km 16, Rod. Ilhéus-Itabuna, CEP 45662-000, Ilhéus, Bahia, Brasil \\ ${ }^{2}$ Departamento de Ciências Biológicas, Universidade Estadual de Feira de Santana - UEFS \\ ${ }^{3}$ Departamento de Ciências Agrárias e Ambientais, Universidade Estadual de Santa Cruz - UESC \\ ${ }^{4}$ Autor para correspondência: Henrique Fernandes de Magalhães, e-mail: henri_mag@hotmail.com
}

\begin{abstract}
MAGALHÃES, H.F., COSTA NETO, E.M. \& SCHIAVETTI, A. Fishing knowledge related to the catch of crabs (Decapoda: Brachyura) in the municipality of Conde, Bahia State. Biota Neotrop. 11(2): http://www. biotaneotropica.org.br/v11n2/en/abstract?article+bn01011022011
\end{abstract}

\begin{abstract}
This study presents the empirical knowledge of artisanal fishermen from the municipality of Conde, Northeastern Bahia State, regarding the catch of brachyuran crustaceans of economic importance in the region. The local techniques and tools used by crab gatherers, as well as the aspects of trade and territoriality are discussed. The data were obtained from September 2007 to December 2009 through open-ended recorded interviews and behavioral observation, considering the usual methods for ethnographic work. A total of 57 artisanal fishermen of both genders and aged between 10 and 78 years were interviewed. The data were analyzed to compare the information provided by participants with those registered in the academic literature. There were four campaigns of biometric analysis of portunid crabs (Callinectes spp.) to determine their sex ratio and morphometry. The capture of resources has a predominantly economic motivation, but is also the main income source of these fishermen. In the biometric analysis of mangrove-crabs, the preference by larger animals was showed regardless the gender. It was also noted the territoriality phenomenon in fishing, though the "fisheries" are freely accessible to all. The artisanal fishing of brachyuran crustaceans of economic importance in Conde is performed with a variety of techniques and equipments that in a direct or indirect way interfere with the fauna and ecosystem dynamics. Although there was some conservation awareness by the participants of this study, different management attitudes were showed. Further studies are needed for the management and sustainable use of these fishery resources, thus providing benefits to local communities.

Keywords: empirical fishing knowledge, sustainability, Northern coast of Bahia.
\end{abstract}

MAGALHÃES, H.F., COSTA NETO, E.M., \& SCHIAVETTI, A. Saberes pesqueiros relacionados à coleta de siris e caranguejos (Decapoda: Brachyura) no município de Conde, Estado da Bahia. Biota Neotrop. 11(2): http://www.biotaneotropica.org.br/v11n2/pt/abstract?article+bn01011022011

Resumo: O presente artigo registra os saberes pesqueiros empíricos relacionados com o extrativismo de crustáceos braquiúros de importância econômica no município de Conde, Litoral Norte do Estado da Bahia, caracterizando as técnicas e apetrechos empregados na coleta desses crustáceos, além de discutir aspectos ligados à comercialização do pescado e à territorialidade. Os dados foram obtidos no período de setembro de 2007 a dezembro de 2009 mediante entrevistas semi-estruturadas e observações comportamentais, recorrendo-se às técnicas usuais de registro etnográfico. Foram entrevistados 57 pescadores artesanais, de ambos os gêneros, com idades entre 10 e 78 anos. Os dados foram analisados qualitativamente comparando-se os saberes locais com a literatura acadêmica especializada. Foram realizadas quatro campanhas de análise biométrica de siris (Callinectes spp.) com o objetivo de determinar a proporção sexual e morfométrica. Os resultados mostram que a coleta de crustáceos tem uma motivação predominantemente econômica, embora também seja a principal fonte de subsistência local. Na análise biométrica dos indivíduos de siris foi evidenciada a preferência por animais de porte maior, independente do gênero. A pesca artesanal dos crustáceos em Conde é realizada com uma diversidade de técnicas e apetrechos que, de forma direta ou indireta, interfere na dinâmica faunística e ecossistêmica. Embora haja uma consciência conservacionista por parte dos participantes da pesquisa, evidenciam-se diferentes atitudes de manejo. Trabalhos posteriores podem vir a fornecer subsídios visando ao manejo e uso sustentável destes recursos pesqueiros, vindo a beneficiar as comunidades locais.

Palavras-chave: conhecimento pesqueiro empírico, sustentabilidade, Litoral Norte da Bahia. 


\section{Introdução}

A pesca artesanal ocupa grande parte da capacidade de trabalho das comunidades litorâneas, seja na captura, no beneficiamento ou na comercialização do pescado. A atividade pesqueira artesanal requer dos indivíduos um conhecimento que possibilita a utilização dos recursos naturais e garante a sustentabilidade desta práxis. Marques (1993) afirma que os pescadores portam o saber e o saber-fazer relacionados com a estrutura e a função do(s) ecossistema(s) ao qual estão vinculados. O convívio diário do indivíduo com o ambiente aquático, somado à necessidade de exploração, lapidou a experiência do pescador, que inclui uma ampla percepção acerca do meio ambiente e seus elementos (Diegues 1998, Cordell 2001).

Os crustáceos são animais bem característicos de regiões de manguezais e desempenham papel na dinâmica do ecossistema, não só pela função na cadeia alimentar, como também porque alguns deles, os braquiúros, atuam no processamento da serapilheira (Nordhaus et al. 2006), no fluxo energético (Conde et al. 2000, Wolff et al. 2000), na bioturbação do sedimento (Amouroux \& Tavares 2005) e na ciclagem do carbono e da matéria orgânica (Guest et al. 2006). Constituem um grupo diverso e fazem parte de uma das maiores biomassas no ecossistema marinho (Ruppert et al. 2005).

Culturalmente, esse grupo de animais é utilizado para fins diversos, como artesanato (Cascudo 1972, Farias \& Rocha-Barreira 2007), fonte de renda e proteínas (Reitermajer 1996, Nomura 2001, Souto 2004), na medicina popular (Lages Filho 1934, Magalhães 1966, Costa Neto \& Gordiano-Lima 2000) e em atividades lúdicas (Cascudo 1972). As interações que se estabelecem entre os seres humanos e os crustáceos constituem o campo de estudo da etnocarcinologia a qual pode ser definida, parafraseando-se Posey (1986), como a parte da etnozoologia que investiga o conhecimento, a classificação e os modos de utilização dos crustáceos pelas sociedades humanas.

Especialmente no que diz respeito ao uso medicinal, remédios populares elaborados à base de crustáceos têm sido registrados no Brasil desde o século XVII, uma vez que Piso (1957) registrara o uso do aratu contra o veneno do peixe guamaiacu-atinga ( $\mathrm{sic}$ ). Na Amazônia, Gheerbrant (1993) referiu-se à utilização do sarará-dorminhoco (Uca maracoani) para "ensinar a criança a dormir". No Estado do Pará, o caranguejo sarará-pretinho (Uca (Celuca) lepdodactyla) é macerado e, misturado com sebo, serve com unguento para curar feridas (Andrade apud Vergara Filho \& Villas Boas 1996). Embora desacreditada pela ciência médica oficial, a medicina empírica praticada por sociedades indígenas e tradicionais tem grande importância para o desenvolvimento de novas drogas, uma vez que pesquisas farmacológicas demonstram que os caranguejos apresentam substâncias de importância antiinflamatória, antibiótica e anticancerígena (Croft 1986).

Crustáceos braquiúros são recursos pesqueiros com elevado valor sócio-econômico para comunidades que habitam zonas estuarinas, sendo que muitas dessas populações sobrevivem exclusivamente da exploração desses recursos (Schaeffer-Novelli 1995, Jankowsky et al. 2006, Nascimento et al. 2008). Sua coleta é realizada por homens, mulheres e seus filhos, que coletam os animais em corpos d'água, no sedimento lodoso e até sobre as árvores de mangue e em toras caídas. Andrade (1983) e Nordi (1994a, 1994b) afirmam que os catadores de caranguejos, também conhecidos como caranguejeiros ou marisqueiros, apresentam um conhecimento robusto sobre os aspectos etológicos, biológicos e ecológicos dos recursos pesqueiros com os quais interagem, bem como reconhecem a influência que os ciclos lunares e de maré têm sobre estes animais. O conjunto de informações teórico-práticas que esses pescadores apresentam sobre comportamento, hábitos alimentares, reprodução, formas de uso e ecologia dos recursos pesqueiros oferece uma rica fonte de informações sobre como manejar, conservar e utilizar os recursos naturais de maneira mais sustentável. Esse conhecimento está baseado na experiência e seu registro é transmitido especialmente pela tradição oral de geração a geração.

Doria et al. (2008) relatam a existência de várias estratégias tradicionais de manejo da pesca aplicadas pela população ribeirinha e a efetividade desse processo foi observada e avaliada em alguns trabalhos, permitindo o surgimento de políticas com melhores chances de sustentabilidade quando consideram o conhecimento tradicional, complementado pelo conhecimento científico. Por esta razão, torna-se necessário conhecer como as populações tradicionais interpretam e reinterpretam suas tradições e formas de lidar com a natureza, para que essas noções sejam consideradas ao se desenvolver planos de manejo para áreas protegidas e para se manter as estruturas necessárias para que esse equilíbrio com o meio persista, entre elas a disposição das terras e condições econômicas de reprodução da comunidade (Fleury \& Almeida 2007).

No município de Conde, Litoral Norte da Bahia, as atividades de pesca do tipo artesanal merecem destaque pelo fornecimento significativo de recursos pesqueiros tanto para atender à demanda do próprio estado quanto de outras áreas, como Sergipe, Alagoas e mesmo São Paulo e Rio de Janeiro. No entanto, esta região do litoral baiano tem passado por profundas transformações políticas, econômicas, sociais e culturais decorrentes da redefinição de sua inclusão no modelo de desenvolvimento globalizado em que o país está inserido. A expansão do turismo internacional e nacional e as características da paisagem da região provocaram uma redefinição dos projetos do estado e de empresários. Como consequência desta substituição, os conhecimentos empíricos sobre as artes de pesca e as formas de manejo sustentado dos recursos pesqueiros locais podem ser perdidos ao longo das gerações (Costa-Neto et al. 2010).

Neste sentido, o presente trabalho registra os saberes empíricos que pescadores artesanais do município de Conde possuem sobre as espécies de crustáceos braquiúros de interesse econômico, registrando as técnicas locais de captura, além de discutir aspectos ligados à comercialização do pescado e à territorialidade. Este conjunto de informações fornece subsídios para a realização de um ordenamento pesqueiro dos crustáceos braquiúros na região do litoral norte do Estado da Bahia, vindo a beneficiar as comunidades pesqueiras locais.

\section{Material e Métodos}

A área de estudo, esquematizada na Figura 1, inclui-se no domínio da Área de Proteção Ambiental Litoral Norte, no município de Conde-BA, mais precisamente na porção estuarina e costeira do baixo curso do rio Itapicuru $\left(11^{\circ} 48^{\prime} \mathrm{S}, 037^{\circ} 37^{\prime} \mathrm{O}\right)$. O trabalho de campo, em sua etapa inicial, foi desenvolvido no período de setembro de 2007 a outubro de 2008, quando foram realizadas visitas mensais às comunidades de Siribinha, Poças, Sítio do Conde, Ilha das Ostras, Cobó, Buri e Sempre Viva. Na segunda etapa da pesquisa, foram realizadas duas visitas quinzenais às três últimas comunidades, nos meses de fevereiro, maio e dezembro de 2009. Estas comunidades foram selecionadas porque, segundo os próprios sujeitos locais, a coleta de crustáceos (aratus, caranguejos e siris) é predominante em relação às demais comunidades do município de Conde. Ao serem selecionados os meses de visitação, procurou-se contemplar as duas estações do ano reconhecidas pelas comunidades pesqueiras: "verão" (setembro-março) e "inverno" (abril-agosto), correlacionando os dados obtidos durante as mesmas.

Os dados foram obtidos mediante entrevistas semi-estruturadas, baseadas em um roteiro temático (com perguntas abertas e fechadas relacionadas com etnotaxonomia, aspectos biológicos e ecológicos dos crustáceos, apetrechos utilizados na atividade pesqueira, produção, 
organização e territorialidade). Também foram feitas observações comportamentais, acompanhando-se a atividade extrativista de alguns pescadores no estuário. A técnica de turnê (Spradley \& McCurdy 1972) foi empregada, realizando-se excursões guiadas pelos próprios sujeitos às áreas nas quais exerciam a coleta dos recursos pesqueiros.

As entrevistas, individuais ou coletivas, ocorreram em contextos variados e contaram com a participação de 57 indivíduos, sendo 48 homens $(84,2 \%)$ e 9 mulheres $(15,8 \%)$, cujas idades variaram entre 10 e 78 anos. Tratam-se de pescadores e pescadoras especialistas na coleta de aratus, caranguejos e siris, tendo sido contatados segundo a técnica bola-de-neve (Goodman 1961), segundo a qual um especialista local indica outro e assim sucessivamente. As entrevistas foram registradas em gravadores digitais e posteriormente transcritas para análise dos dados. Os indivíduos tiveram acesso ao Termo de Consentimento Livre e Esclarecido, concordando em participar do estudo.

Todo material etnográfico (gravações, transcrições, caderno de campo e fotografias) encontra-se guardado no Laboratório de Etnobiologia e Etnoecologia da Universidade Estadual de Feira de Santana, aos cuidados do curador da seção Etnozoologia do Museu de Zoologia da UEFS.
Os dados etnográficos foram analisados qualitativamente, considerando-se todas as informações citadas pelos sujeitos entrevistados. Os controles foram feitos por meio de testes de verificação de consistência e de validade das respostas, recorrendo-se a entrevistas repetidas em situações sincrônicas e diacrônicas. As primeiras ocorrem quando uma mesma pergunta é feita a indivíduos diferentes em tempos bastante próximos e as segundas, quando uma pergunta é repetida ao mesmo indivíduo em tempos distintos (Marques 1991).

\section{Resultados}

\section{Técnicas empregadas na pesca artesanal}

A atividade pesqueira relacionada com os braquiúros no município de Conde é exercida por meio de técnicas e apetrechos diversos, dependendo do tipo de animal (aratu, caranguejo ou siri) que é capturado. As técnicas e os apetrechos encontram-se descritos na Tabela 1. A maior diversidade de técnicas é direcionada à captura do caranguejo-uçá (Ucides cordatus), sendo que três delas são usadas exclusivamente para este fim: o braceamento, a tapagem e a

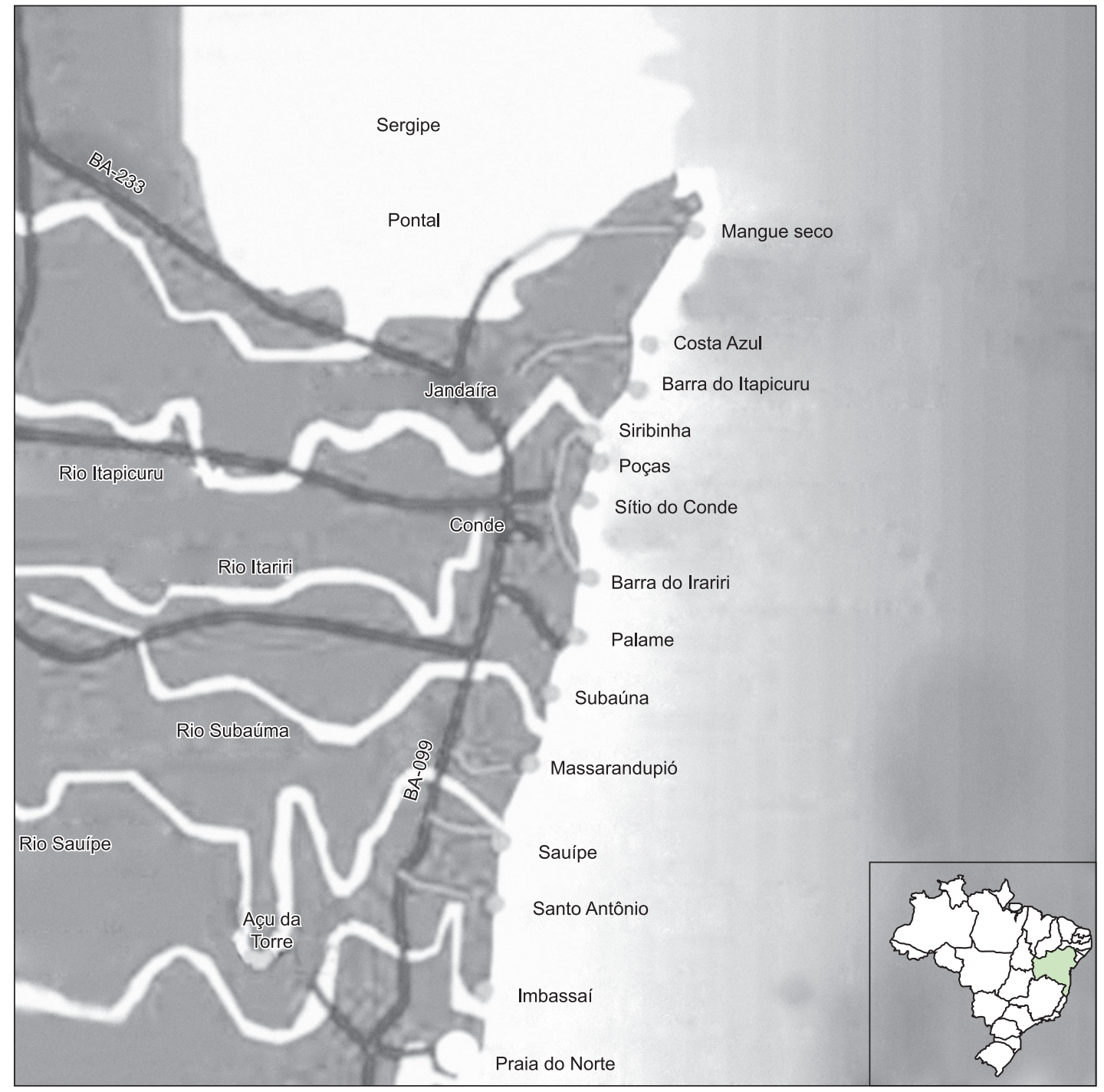

Figura 1. Localização do município de Conde e de algumas das principais comunidades pesqueiras estudadas. Adaptado de Costa-Neto (2000a).

Figure 1. Localization of the municipality of Conde and of some of the main fishing communities studied. Adapted from Costa-Neto (2000a). 
redinha. A coleta do caranguejo-uçá é exercida por todos os homens participantes do estudo $(n=48)$, sendo que parte deles $(n=13)$ se dedica exclusivamente a este extrativismo. Uma pequena parcela $(n=3)$ do total de mulheres abordadas no estudo $(n=9)$ capturam o caranguejo apenas no período da andada com o auxílio de uma armadilha chamada ratoeira.

A técnica do braceamento consiste na introdução do braço do pescador no interior da toca onde o caranguejo se abriga, no intuito de agarrá-lo com a mão. Esse tipo de atividade é exercido somente por homens, que a realizam individualmente ou contando com o auxílio de ajudantes. Em algumas ocasiões, quando o catador não consegue alcançar o caranguejo com seu braço nas primeiras tentativas, ele obstrui a toca e retorna dentro de algum intervalo de tempo (de 30 minutos a uma hora, aproximadamente), mecanismo denominado tapagem.

O desgaste físico proveniente do esforço desprendido para trazer o animal entocado para a superfície do substrato lamoso é o principal motivo alegado pelos catadores de caranguejo-uçá não adeptos da técnica do braceamento $(n=22)$. Por outro lado, a possibilidade de selecionar os indivíduos capturados, a praticidade e o baixo impacto que causa no manguezal foram as principais justificativas apresentadas pelos usuários da referida técnica $(n=26)$ para o fato de esta ser a arte pesqueira mais utilizada para a coleta de Ucides cordatus na região, conforme os depoimentos seguintes:

Em época que não é de andada, só pega eles no braço mesmo. Você sai com um facão, sai cortando mangue adentro, os galhos que tiver na lama, as gaiteiras. Aí enfia a mão na lama, o braço inteiro e pega ele. Quando pegar ele, puxa. Aí vai pegando, juntando e quando terminar vai e joga eles nos viveiros ( $R$., 29 anos).

Eu pego no braço, com a foice. Eu meto o braço e tento pegar. Se conseguir, eu pego. Se não conseguir, eu tapo e depois volto pra pegar. Aí depois de umas meia hora eu vou lá e pego (Seu N., 44 anos).

Eu só uso o braço. Porque eu acho mais fácil. Você vê lá o bicho e pega logo. Não tem que ficar esperando. E você também pode escolher os bichos que você pega (Seu Z. O., 44 anos).

A redinha é também uma arte pesqueira bastante utilizada em Conde, exclusivamente para a captura do caranguejo-uçá. Consiste em uma pequena rede confeccionada com saco de polipropileno trançado, que é colocada na entrada da toca do animal, a fim de que este fique retido nela quando for à superfície. A principal vantagem citada para o uso da redinha, de acordo com os coletores usuários da técnica $(n=17)$, está na praticidade, pois exige pouco esforço físico por parte do pescador. Porém, a maioria dos catadores de Ucides cordatus entrevistados $(n=31)$ reclamou do fato de que essa arte pesqueira não faz distinção do sexo dos animais retidos, uma vez que muitas fêmeas ovígeras e indivíduos jovens acabam capturados Estes, não sendo aproveitados para a venda ou na alimentação, acabam morrendo, o que leva a inferir que o uso da redinha ocasiona uma baixa seletividade, além de ser insustentável para as populações em longo prazo. Alguns catadores experientes, no entanto, dizem saber distinguir a toca dos caranguejos machos e fêmeas, dispondo assim a redinha somente na toca dos primeiros, amenizando, aparentemente, os danos à população local de caranguejos.

Outro dano ambiental que a redinha causa no manguezal é a poluição. Segundo os pescadores e as marisqueiras, restos de polipropileno provenientes de redinhas já utilizadas ficam acumulados no manguezal, poluindo o ambiente e até atrapalhando o exercício da atividade pesqueira, o que se evidencia no trecho a seguir:

Não tem um saquinho de náilon, aqueles que desfia todo? Então coloca no buraco, dá um nozinho numa ponta aqui e outra aqui. Aqui o caranguejo sobe, aqui é a puã dele [nome local para a quela], enlinha aqui. Aí não sorta. Eaí se o dono não achar, aquilo se acaba por lá. [...] E aí eles corta a parte que tá o caranguejo e o resto, aquela bagunça, deixa no mangue. Aí aquilo já é prejuízo pro mangue. Aí deixa ali. Aí você chega ali e no mangue tá cheio daquelas bagaceiras de saco. Ali já vem outro e ali pega e já se engancha e aí pronto. E acabou. E aí o prejuízo tá aí. E aí vai deixar de render. Essa pesca aí, eu mesmo não sou de acordo não (Seu F., 41 anos).

Quanto aos covos, estes são armadilhas de fundo semi-fixas confeccionadas com palheta rígida, com uma abertura em uma das extremidades, apresentando formato cilíndrico. Na região de Conde, as palhetas são fabricadas a partir da entrecasca da piaçava (Attalea funifera Mart.), conhecida localmente como "quitanda", e são amarradas umas às outras com raízes ("cipós") da timborana (Araceae). Essas armadinhas são de dois tamanhos: o covo maior é utilizado para capturar siris (Callinectes exasperatus, Callinectes danae) e caranguejos-uçás (em época de "andada"), embora outros recursos pesqueiros não visados também entrem na armadilha, como aratus (Goniopsis cruentata) e "moreias" (Bathygobius soporator, Gobiidae), os quais são mais especificamente capturados usando-se covos menores. Para a captura de siris, os pescadores geralmente iscam os covos com restos de peixes ou de

Tabela 1. Descrição dos principais apetrechos e técnicas utilizadas na pesca artesanal de crustáceos braquiúros de importância econômica na região de Conde, Estado da Bahia.

Table 1. Description of the main techniques used in the artisanal fishing of brachiuran crustaceans of economical importance in the region of Conde, Bahia State.

\begin{tabular}{|c|c|c|}
\hline Arte de pesca & Descrição & Recurso capturado \\
\hline Braceamento & Introduz-se o braço inteiro na toca onde o caranguejo se encontra. & $\begin{array}{l}\text { Caranguejo-uçá } \\
\text { (Ucides cordatus) }\end{array}$ \\
\hline Covo grande & $\begin{array}{l}\text { Armadilha de fundo semi-fixa, cilíndrica, confeccionada com palheta rígida, com uma } \\
\text { sanga (abertura) em uma das extremidades. }\end{array}$ & $\begin{array}{l}\text { Siri-do-mangue } \\
\text { (Callinectes exasperates, } \\
\text { Callinectes danae), siri-do-rio } \\
\text { (C. danae), caranguejo-uçá }\end{array}$ \\
\hline Covo pequeno & $\begin{array}{l}\text { Armadilha de fundo semi-fixa, confeccionada com palheta rígida, com uma sanga } \\
\text { (abertura) em uma das extremidades, apresentando formado cilíndrico. }\end{array}$ & Aratu (Goniopsis cruentata) \\
\hline Linha & $\begin{array}{l}\text { Utiliza-se a linha, geralmente amarrada a um galho de árvore do mangue, onde se } \\
\text { coloca uma isca na ponta da linha e se espera o aratu. }\end{array}$ & Aratu \\
\hline Ratoeira & $\begin{array}{l}\text { Espécie de alçapão feito com lata de óleo ou madeira, utilizado na captura de } \\
\text { caranguejos. }\end{array}$ & $\begin{array}{l}\text { Caranguejo gaiamum } \\
\text { (Cardisoma guanhumi), } \\
\text { caranguejo-uçá }\end{array}$ \\
\hline Redinha & Armadilha fixa feita de saco de estopa, colocada na entrada das tocas de caranguejos. & Caranguejo-uçá \\
\hline Tapagem & Obstrução da toca. & Caranguejo-uçá \\
\hline
\end{tabular}


outros crustáceos, como caranguejos, aratus, gajés ou chama-marés (Uca sp.) e até mesmo de siris; enquanto que para se capturar aratus as iscas são quase sempre de origem vegetal, como coco verde.

Nesse tipo de arte pesqueira, ao contrário das atividades descritas anteriormente, tanto homens quanto mulheres participam, individualmente ou em grupo. A predominância do exercício da atividade pesqueira ainda é masculina, embora a participação feminina venha crescendo na pesca artesanal (Hoje em dia tem mais isso não: é homem, é mulher. É todo mundo, Seu C., 65 anos).

A ratoeira é uma espécie de alçapão feito com lata de óleo ou madeira, utilizada especialmente na captura de Cardisoma guanhumi (Pra pegar gaiamum é só de ratoeira, J., 13 anos), sendo raras vezes empregada na coleta de caranguejos-uçás. Nesse tipo de arte pesqueira, o apetrecho é iscado com materiais de origem vegetal, como coco verde ou simplesmente folhas. A principal vantagem desse tipo de apetrecho é o baixo custo, uma vez que ele é fabricado a partir de recursos de fácil acessibilidade: Ratoeira se faz com pedaço de madeira, lata de óleo. Todo mundo tem isso em casa, né?, Seu C., 65 anos. Os pescadores e pescadoras que fazem uso dessa arte pesqueira $(n=16)$ citaram também o fato de esta ser uma armadilha não-fixa, que não estraga facilmente, como é o caso do covo, e de se poder selecionar os caranguejos a serem utilizados posteriormente (A ratoeira não prejudica tanto, porque você pega o bicho vivo. Você pegando uma fêmea ovada, você querendo ela tá viva, aí você solta, Seu J., 46 anos). Logo, a relação custo/benefício ecológico voltada à seleção da população capturada é favorável do ponto de vista conservacionista.

A coleta de aratus também pode ser feita com o uso de outro tipo de apetrecho, além da utilização de covos: a pesca com linha. Embora esta prática seja menos abundante que a tradicional pesca com covos, algumas mulheres que não pescam com frequência e, logo, não visam ao retorno comercial, a utilizam bastante. Nesse tipo de técnica, utilizada predominantemente por mulheres (Pegar aratué mais com mulher mesmo, Seu C., 65 anos), amarra-se a linha de náilon a um galho de árvore do mangue, onde se coloca uma isca na ponta da linha e espera-se o aratu agarrar. Na região de Conde, a maioria das mulheres entrevistadas ( $\mathrm{n}=7$ ) afirmou fazer uso da técnica. Estas marisqueiras, a fim de atraírem os aratus para a armadilha, produzem sons, seja entoando canções ou batendo nas folhas das árvores do mangue com um galho, como demonstram os trechos abaixo:

[...] tem outro jeito de pegar o aratu também, que é no balde. Bota lá o balde, aí pega um quarto de caranguejo ou siri, qualquer coisa, amarra numa corda, numa cordinha pequena. Pequena não, fina. Aí fica batendo no chão, com um bocado de folha que é pra chamar eles. Então quando eles sai, eles vem direto pra corda por causa da isca. Aí pega e joga dentro do balde (R., 29 anos).

A gente bota a linha lá com a isca e vai assoviando, esperando ele chegar, ou fazendo zoada nos pau com as folhas. Aí eles vêm tudo doido (Dona A., 55 anos).

Entre os pescadores artesanais de Conde, a crença na intervenção divina como um fator atuante na inesgotabilidade dos recursos pesqueiros é quase um consenso. Esse fenômeno é alicerçado pela dependência direta que a população pesqueira local tem em relação ao ecossistema e pela falta de uma alternativa de subsistência aparente, caso os recursos venham mesmo a se esgotar, aliado a um forte sentimento religioso, como demonstram os depoimentos abaixo:

Olha, o que é de Deus não se acaba. Diminui um pouco, mas não acaba (Seu E. V., 75 anos).

Rapaz, o que atrapalha hoje é porque a população cresceu. A população cresceu e é muita gente que colhe esses mariscos, né? Aí por isso a gente acha mais difícil [...], mas o que é de Deus num se acaba, né? (Seu N., 44 anos).

\section{Comercialização}

A maior parte dos pescadores e marisqueiras entrevistados afirmou exercer a pesca visando o comércio, uma vez que a atividade pesqueira constitui a principal, se não a única, fonte de renda para as famílias das comunidades visitadas ("Nós vive disso aî", $R$., 29 anos), embora seja também a principal estratégia de subsistência. Os siris são coletados no "inverno", caranguejos no "verão", enquanto aratus são capturados e comercializados o ano todo.

A comercialização de caranguejos, siris e aratus pode ser feita tanto pelos próprios pescadores e marisqueiras, quando os animais processados ou in vivo (Figura 2a,d) são vendidos diretamente ao comprador nas residências ou na feira livre da cidade do Conde, realizada aos sábados, ou por atravessadores, que compram a produção dos coletores por um valor muito abaixo do mercado e revendem com ganhos significativos. Os caranguejos uçá e gaiamum são vendidos em cordas contendo cinco e 10 (ou 12) indivíduos, respectivamente; siris são vendidos na forma de cento (conjunto de 100 indivíduos), enquanto os aratus podem ser comercializados já processados no que se conhece como "catado" (quando a carne pré-cozida é condicionada em sacos plásticos de $1 \mathrm{~kg}$ ), ou em cento.

Os caranguejos uçá e gaiamum podem ser mantidos vivos em viveiros, sendo alimentados com frutas e outros itens até atingirem o ponto para venda ou consumo (Figura 3a-b). O valor comercial dos produtos, segundo os entrevistados, não sofre grandes variações ao longo do ano (É esse preço aí o ano todo, Dona E. L., 72 anos). A corda do uçá varia de $\mathrm{R} \$ 2,50$ a $\mathrm{R} \$ 3,00$; a corda do gaiamum custa entre $\mathrm{R} \$ 8,00$ a $\mathrm{R} \$ 10,00$, com indivíduos de porte pequeno, e entre $\mathrm{R} \$ 20,00$ a $\mathrm{R} \$ 25,00$, com animais de porte médio e grande; o cento de siris, principalmente de siris-do-mangue (o mais comercializado localmente), pode variar de $\mathrm{R} \$ 25,00$ a $\mathrm{R} \$ 30,00$; e o aratu é pouco comercializado em cento, devido ao baixo valor de mercado $(\mathrm{R} \$ 4,00$ a $R \$ 5,00$ ) sendo mais vendido já catado, atingindo preços que variam de $\mathrm{R} \$ 8,00$ a $\mathrm{R} \$ 12,00$.

Muitos catadores e, principalmente, catadoras em Conde afirmaram que o aratu, mesmo catado, não apresenta uma comercialização compensatória, uma vez que a atividade de "catação" exige muito esforço e disponibilidade de tempo (É muito trabalho pra pouco dinheiro, Dona E. L., 72 anos).

\section{Territorialidade}

Em Conde, segundo os entrevistados, não há relação de posse no que se refere aos locais de pesca, denominados localmente de pesqueiros. Aparentemente, o acesso a esses sítios de pesca é livre a toda e qualquer pessoa que deseje pescar, mesmo que pertença a outra comunidade ou mesmo de cidade diferente, o que pode ser evidenciado nos seguintes depoimentos:

Rapaz, aqui tem dono não. Quem chegar bota o barco (I., 21 anos).

É proibido não. Pode ir e pegar em qualquer lugar (Dona A., 54 anos).

No mangue pode pescar em todo lugar. Ele é de todos. No mangue, ninguém manda em ninguém (Seu E. V., 75 anos).

Apesar de os sítios de pesca serem de uso comum nas comunidades pesqueiras onde o presente estudo foi desenvolvido, o acesso a eles pode ser limitado por fatores sócio-culturais e econômicos. Por exemplo, existem os segredos de pesca e a habilidade de manejar determinado recurso disponível no ambiente, que nem todos possuem (Nem toda arte todo mundo sabe, né?, Seu C., 65 anos); e o acesso aos apetrechos e embarcações, uma vez que apenas os indivíduos que participam das associações locais podem usar (Aqui, por exemplo, quem não é da associação não tem direito a usar os barcos deles, Seu J., 46 anos). No entanto, essa medida, apesar de muito comum 
localmente, nem sempre se mostra bem sucedida (Às vez, tem lugares que nem todo mundo pesca. Aí a gente vai, bota nosso covo, mas tem sempre um espertinho que vai lá e pega, né?, Seu AN., 71 anos).

Entre os pescadores artesanais de Conde há também o estabelecimento de regras sociais baseadas no respeito $(E \mathrm{em}$ relação a esses lugares marcados, por exemplo, cada um vai lá e bota seu covo num lugar. Tem alguma maneira que eles usam pra identificar seu covo. É proibido botar covo num lugar onde já tenha outro, Dona A., 54 anos). A existência dessas regras é justificada pela limitação no número de "pesqueiros" para um número cada vez mais crescente de pescadores. No entanto, nem sempre essas são respeitadas, o que acaba gerando conflitos ocasionais (Num é sempre não, mas às vezes aparece um querendo ser mais espertinho que os outros. Toma covo que não é dele, pescaria que não é dele. Aí a confusão tá feita, Seu A. N., 71 anos).

\section{Discussão}

A pesca artesanal de crustáceos braquiúros de importância econômica em Conde é realizada com uma diversidade de técnicas e apetrechos. No exercício dessas atividades, a principal motivação evidenciada é a econômica, uma vez que a pesca artesanal é a principal fonte de renda para as comunidades de pescadores do município.
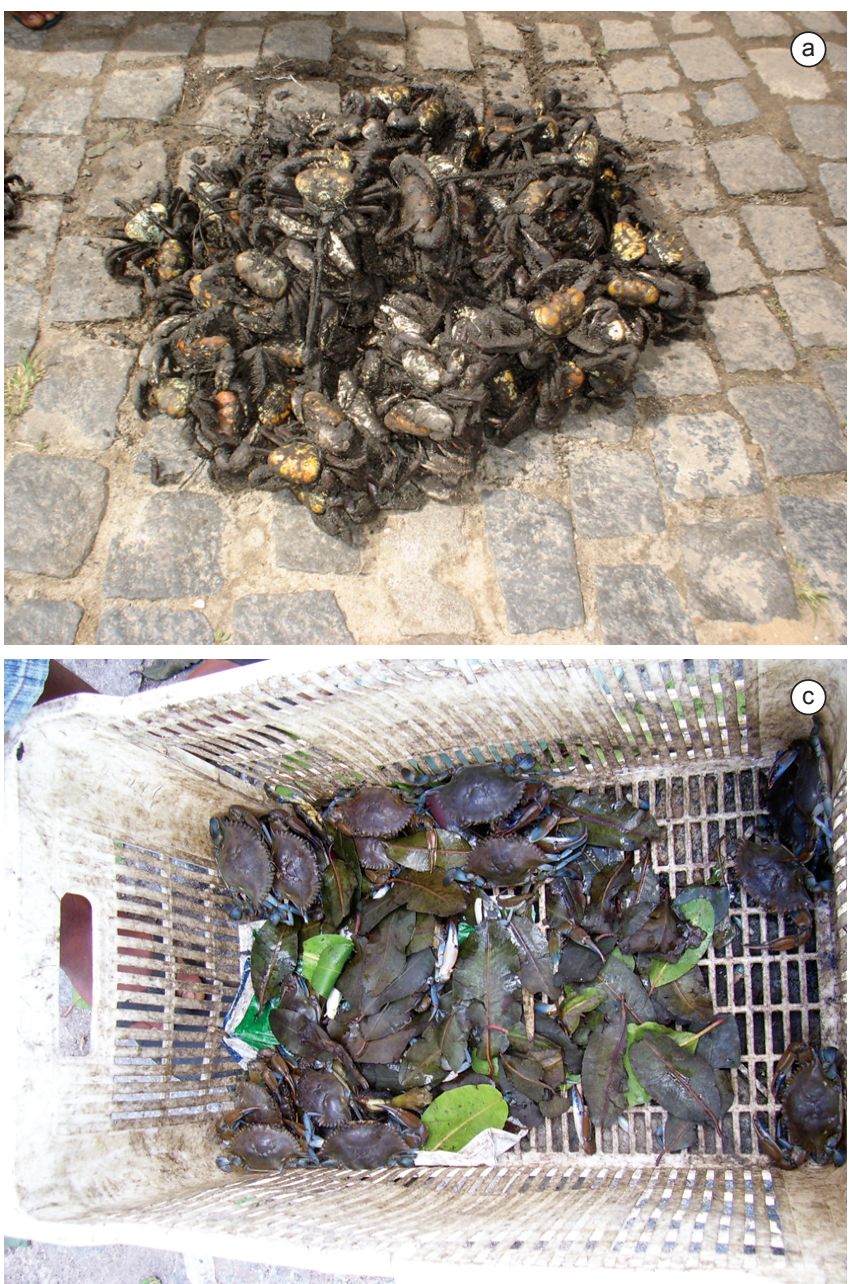

A coleta de Ucides cordatus é considerada uma das atividades extrativistas mais importantes não apenas em Conde, mas em todo o país (Saint-Paul 2006), constituindo fonte de renda para parte da população com baixo poder aquisitivo que habita regiões estuarinas (Wolff et al. 2000, Glaser 2003, Alves \& Nishida 2003, Glaser \& Diele 2004). Três das técnicas registradas são empregadas exclusivamente na captura deste caranguejo: braceamento, tapagem e redinha. A técnica do braceamento (ou braceado) parece ser uma herança dos índios Tupinambá que habitavam a costa brasileira. Gabriel Soares de Souza, em seus registros em 1587, já fazia referência aos "índios mariscadores com o braço nu" (Souza 2000).

Em regiões estuarinas do Estado da Paraíba, a ratoeira é empregada também na pesca do caranguejo-uçá, além do gaiamum (Nordi 1994b). Na literatura consultada, a ratoeira aparece como o principal apetrecho usado na captura de gaiamuns (Soffiati 2001, Franco 2002, Botelho \& Santos 2005, Brunet 2006).

Com relação à redinha, seu uso indiscriminado, aliado ao aumento do número de catadores, maximiza a pressão de coleta, ao mesmo tempo que promove a redução do tamanho médio de Ucides cordatus, levando a uma prevalência de caranguejos adultos com menor tamanho médio e alterando a estrutura populacional, o que compromete os elos manguezal-caranguejo e homem-caranguejo (Jankowsky et al. 2006). Castilho-Westphal et al. (2008), em um
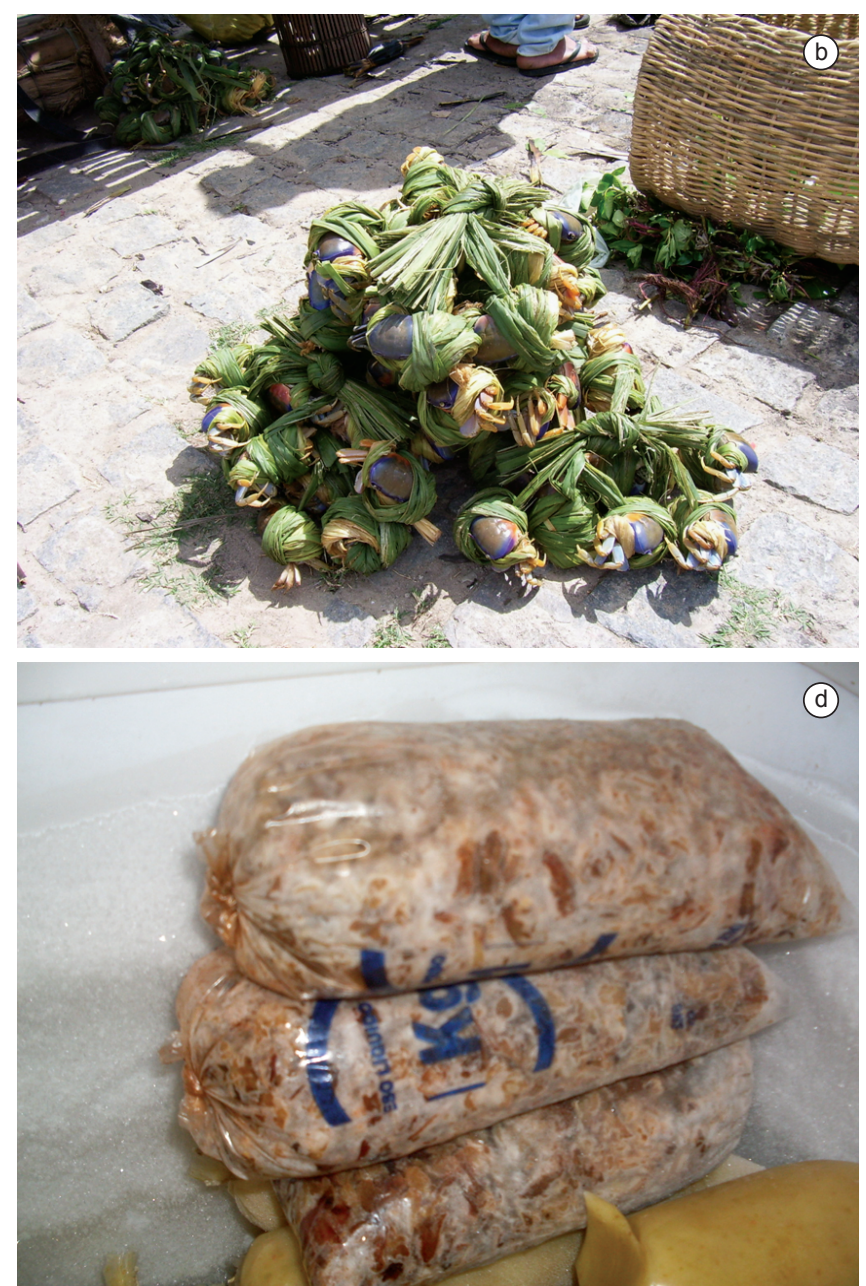

Figura 2. Modos de comercialização de crustáceos braquiúros em Conde: a) cordas de caranguejos-uçás (Ucides cordatus); b) cordas de gaiamuns (Cardisoma guanhumi); c) cento de siris-do-mangue (Callinectes spp.); d) aratus (Goniopsis cruentata) catados estocados para comercialização. Fotos: Henrique F. Magalhães.

Figure 2. Selling of brachyuran crustaceans in Conde: a) ropes of mangrove red crabs (Ucides cordatus); b) ropes of blue land crab (Cardisoma guanhumi); c) cent of blue crabs (Callinectes spp.); d) mangrove root crabs (Goniopsis cruentata) collected and stocked for selling. Photographs by Henrique F. Magalhães. 
trabalho de revisão acerca do estado da arte das pesquisas sobre esta espécie, citam o trabalho de Passos \& Beneditto (2005) realizado no manguezal de Gargaú (Rio de Janeiro) e de Diele et al. (2005) no estuário de Caetés, norte do Brasil, que abordam a exploração comercial durante todo o ano, em que a redinha é o principal mecanismo de captura, embora sua utilização seja proibida por legislação federal. Apesar disso, o tipo de captura praticada por esses pescadores exclui fêmeas ovígeras e espécimes com largura de carapaça inferior a $6,0 \mathrm{~cm}$, medida mínima regulamentada pelo IBAMA para captura de caranguejos-uçás (Art. $3^{\circ}$, Portaria número 034/03-N, de 24 de junho de 2003), uma vez que a demanda é por exemplares maiores que possuem maior valor de mercado. Um estudo realizado por Botelho et al. (2000) com catadores de $U$. cordatus no estuário do rio Formoso, Pernambuco, revelou que cada catador utiliza, em média, 130 redinhas/dia, dedicando 18 dias por mês à cata deste crustáceo. Os autores dizem que

Ao longo de um ano, cada catador utiliza 28.080 redinhas, que correspondem a cerca de $17 \mathrm{~kg}$ de fios de nylon que, após a captura, são jogados no manguezal ou no seu entorno, além, de $42.000 \mathrm{~m}$ lineares de raiz de mangue cortada para a fixação das armadilhas, sem contar com a quantidade de mangue cortado para ser utilizado nas marcações destas, além das armadilhas perdidas [...], as quais ficaram fixadas nas tocas (BOTELHO et al. 2000, p. 55-71).
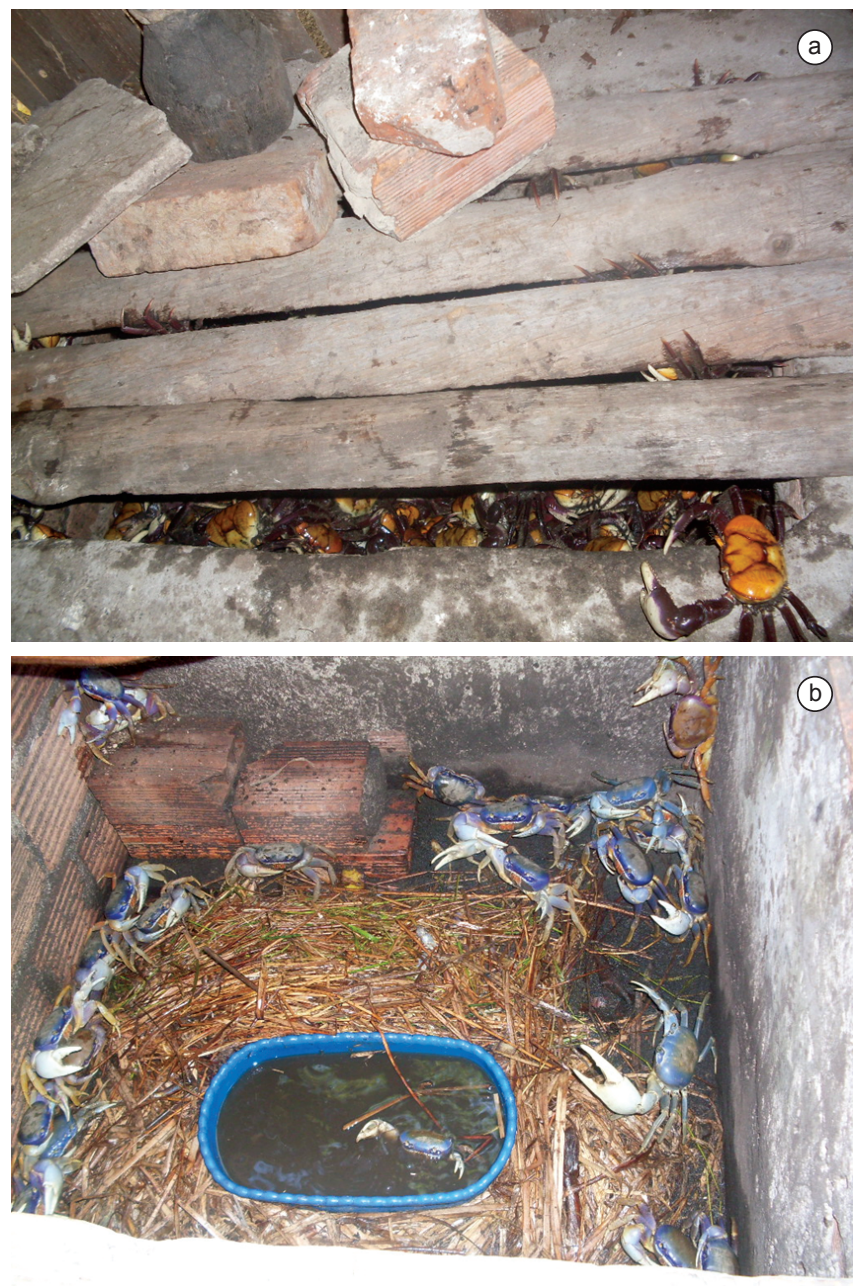

Figura 3. Viveiros para a) caranguejos-uçás; e b) gaiamuns. Fotos: Henrique F. de Magalhães.

Figure 3. Shelters for a) mangrove red crabs; and b) blue land crabs. Photographs by Henrique F. Magalhães.
Embora haja uma consciência conservacionista por parte dos participantes da pesquisa (não coletar fêmeas “ovadas" e indivíduos jovens, por exemplo), o que se evidenciou em Conde foram atitudes de manejo e não uma preocupação direta com a questão da conservação. Um aspecto que deve ser levado em consideração é o sistema de crenças local, uma vez que os pescadores creem na inesgotabilidade dos recursos pesqueiros. Neste sentido, Colding \& Folk (1997) afirmam que a religiosidade é um elemento relevante a ser analisado em sistemas de conservação de recursos naturais e ecossistemas.

Verifica-se que a predominância do exercício da atividade pesqueira em Conde ainda é masculina, embora a participação feminina venha crescendo na pesca artesanal. Estudos de comunidades pesqueiras em geral ainda tendem a enfatizar a participação masculina e seus pontos de vista, em detrimento da contribuição feminina (Woortmann 1992), embora essa desempenhe papel fundamental no suporte ou complemento da atividade pesqueira (Alencar 1993). Porém, do ponto de vista ecológico, esse fenômeno significa um aumento da pressão sobre os recursos explorados por ambos os gêneros, pondo-os em risco de esgotamento em seus ambientes naturais (Hardin 1968) caso não haja formas de manejo adequadas, como medidas compensatórias.

No que diz respeito à captura de siris do gênero Callinectes, a literatura consultada não registra o uso de covos, o que talvez indique endemismo da utilização desse apetrecho na região de Conde. Apetrechos, como o espinhel (groseira) e o manzuá, também são utilizados na pesca artesanal de siris ao longo da costa brasileira (Severino-Rodrigues et al. 2001, Souto \& Marques 2006, Garcez 2007). Em Conde, tais apetrechos são utilizados principalmente para a captura de peixes e, muito raramente, para siris.

A utilização da linha na pesca artesanal de aratus parece ser um fenômeno bastante difundido, pelo menos ao longo da costa do Nordeste Brasileiro, uma vez que em trabalhos como os de Moura et al. (2000) e de Santos et al. (2001), nos litorais Norte e Sul do Estado de Pernambuco, respectivamente, tal prática é evidenciada como principal na captura de aratus. Nesses mesmos estudos, há também registro dos tipos de iscas utilizadas (tripa de galinha, restos de peixe e ostra) e do hábito de produzir barulho para atrair os animais. Segundo Moura et al. (2000), a utilização deste método representa um importante recurso na conservação do estoque desta espécie, devido à seletividade em relação aos juvenis.

Quanto à comercialização, a intermediação do pescado em comunidades pesqueiras ao longo da costa brasileira apresenta-se com diferentes graus de hierarquia, formas de organização e atuação, sendo semelhante na estratégia de pagar preços baixos aos produtores e progressivamente mais altos a cada nível hierárquico da cadeia de comercialização (Nordi 1994b, Alves \& Nishida 2003, Souto \& Marques 2006). Por causa disso, muitos dos pescadores de Conde disseram preferir vender seu próprio pescado, embora muitas vezes se vejam obrigados a recorrer aos atravessadores por falta de opção. A inexistência de um sistema de cooperativa eficiente, fruto da falta de união e organização das comunidades, aliada à condição de precariedade da pesca artesanal, faz com que outras formas de comercialização se tornem praticamente inviáveis, uma vez que os pescadores temem perder parte de sua produção ou toda ela devido à falta de condições adequadas de beneficiamento e armazenagem do pescado.

A apropriação de um recurso torna-se, assim, um ato produtivo e cultural, simultaneamente (Cunha 1989 apud Souto \& Marques 2006). De fato, comunidades pesqueiras apresentam direitos de propriedade e de usos exclusivos de recursos, coordenados por regras variadas em termos de organização e prática que acabam afastando indivíduos ou grupos uns dos outros (Cordell \& MacKean 1986, Cordell 2001, 
Marques 1995, 2001, Begossi 1995), o que constitui, segundo Odum (2001), a territorialidade.

Em relação à manutenção dos segredos de pesca (Maldonado 1999), em Conde, estes visam evitar a presença de competidores e, assim, garantir um maior rendimento na explotação do recurso. Esse tipo de mecanismo apresenta relevância com a afirmação de Hardin (1968): "[...]a liberdade em relação a recursos comuns gera ruína de todos". Hardin (1968) em seu trabalho acerca da "Tragédia dos Comuns" afirmou que recursos de acesso comum tendem à extinção devido à competição. No entanto, ele parece não levar em consideração fatores culturais (Fenny et al. 2001, Burke 2001), pois grupos e comunidades locais que utilizam esses recursos comuns possuem habilidades em organizá-los e manejá-los de forma efetiva (Berkes 1985). Esses fatores, incluindo a territorialidade, acabariam por regular o acesso aos mesmos (Diegues \& Arruda 2001).

Entre os pescadores artesanais de Conde há também o estabelecimento de regras sociais baseadas no respeito, o que constitui, de acordo com Cordell (2001), um código de honra que forma e regula as relações da pesca em comunidades pesqueiras. Estudos como o de Hartmann (1989) na região amazônica e de Marques (2001) na região do Complexo Estuarino-Lagunar Mundaú-Manguaba (Alagoas), também registraram conflitos dessa natureza, o que parece indicar que estes são bastante comuns em comunidades pesqueiras.

Sugere-se a criação da Reserva Extrativista Flúvio-Marinha do município de Conde, o que permitirá às comunidades pesqueiras do estuário do rio Itapicuru e região costeira adjacente a possibilidade de empoderamento e apropriação de seus conhecimentos tradicionais de modo a estabelecer uma perspectiva futura de sua perpetuação e da conservação da biodiversidade no Litoral Norte do Estado da Bahia.

\section{Agradecimentos}

Os autores agradecem à Coordenação de Aperfeiçoamento de Pessoal de Nível Superior (CAPES) e ao Instituto do Meio Ambiente da Bahia (IMA) pelo suporte financeiro a pesquisa; e ao prof. MSc César Carqueija (FTC - Salvador) pelas identificações taxonômicas de espécimes coletados. Um agradecimento especial às comunidades pesqueiras do município de Conde (BA) visitadas no decorrer do projeto, pela participação e hospitalidade, sem as quais seria impossível a viabilização do trabalho.

\section{Referências Bibliográficas}

ANDRADE, J. 1983. Folclore na região do Pará: teredos na alimentação/profissões ribeirinhas. Escola de Folclore, São Paulo.

ALENCAR, E.F. 1993. Gênero e trabalho nas sociedades pesqueiras. In Povos das águas: realidade e perspectivas na Amazônia (L. Furtado, W. Leitão \& A.F. Melo, orgs.). Museu Paraense Emílio Goeldi, Belém, p.63-81.

ALVES, R.R.N. \& NISHIDA, A.K. 2003. Aspectos socioeconômicos e percepção ambiental dos catadores de caranguejo-uçá Ucides cordatus cordatus (L., 1763) (Decapoda, Brachyura) do estuário de Rio Mamanguape, nordeste do Brasil. Interciencia 28(1):1-8.

AMOUROUX, J.M. \& TAVARES, M. 2005. Natural recovery of Amazonian mangrove Forest as revealed by brachyuran crab fauna: preliminary description. Vie Milieu-Life Envir. 55(2):71-79.

BEGOSSI, A. 1995. Fishing spots and sea tenure: incipient forms of local management in Atlantic Forest coastal communities. Hum. Ecol. 23:387-405. http://dx.doi.org/10.1007/BF01190138

BERKES, F. 1985. Fishermen and "The Tragedy of the Commons". Environ. Conser. 12(3):199-206. http://dx.doi.org/10.1017/S0376892900015939

BOTELHO, E.R.O., SANTOS, M.C.F \& PONTES, A.C.P. 2000. Algumas considerações sobre o uso da redinha na captura do caranguejo-uçá, Ucides cordatus (Linnaeus, 1763) no litoral sul de Pernambuco - Brasil. Bol. Tec. Cient. CEPENE 8(1):55-71.
BOTELHO, E.R.O. \& SANTOS, M.C.F. 2005. A cata de crustáceos e moluscos no manguezal do Rio Camaragibe - Estado de Alagoas: aspectos sócio-ambiental e técnico-econômico. Bol. Tec. Cient. CEPENE 13(2):77-96.

BOTELHO, E.R.O., SANTOS, M.C.F \& PONTES, A.C.P. 2000. Algumas considerações sobre o uso da redinha na captura do caranguejo-uçá, Ucides cordatus (Linnaeus, 1763) no litoral sul de Pernambuco - Brasil. Bol. Tec. Cient. CEPENE 8(1):55-71.

BRUNET, J.M.S. 2006. Aratus, caranguejos, siris e guaiamuns, animais do manguezal: uma etnografia dos saberes, técnicas e práticas dos jovens da comunidade pesqueira de Baiacu (Ilha de Itaparica-BA). Dissertação de mestrado, Universidade Federal da Bahia, Salvador.

BURKE, B.E. 2001. Hardin revisited: a critical look at perception and the logic of the commons. Hum. Ecol. 29(4):449-476. http://dx.doi. org/10.1023/A:1013145905257

CASCUDO, L.C. 1972. Dicionário do folclore brasileiro. Ediouro, Rio de Janeiro.

CAStilho-WestPhal, G.G., Ostrensky, A., PIE, M.R. \& BOEGER, W.A. 2008. Estado da arte das pesquisas com o caranguejo-uçá, Ucides cordatus. Arch. Vet. Sci. 13(2):151-166.

COLDING, J. \& FOLK, C. 1997. The relations among threatened species, their protections and taboos. Conser. Ecol. 1(6):1-19.

CONDE, J.E., TOGNELlA, M.M., PAES, E.T., SOARES, M.L.G., LOURO, I.A. \& SCHAEFFER-NOVELLI, Y. 2000. Population and life history features of the crab Aratus pisonii (Decapoda: Grapsidae) in a subtropical estuary. Interciência 25(3):151-158.

CORDELL, J. 2001. Marginalidade social e apropriação territorial marítima na Bahia. In Espaços e recursos naturais de uso comum (A.C.S. Diegues \& A.C.C. Moreira, orgs.). NUPAUB-USP, São Paulo, p. 139-160.

CORDELL, J. \& MACKEAN, M.A. 1986. Sea tenure in Bahia, Brazil. In Conference on Common Property Resource Management. National Academy Press, Washington, p. 85-112.

COSTA-NETO, E.M. \& GORDIANO-LIMA, K.L. 2000. Contribuição ao estudo da interação entre pescadores e caranguejos (Crustacea, Decapoda, Brachyura): considerações etnobiológicas em uma comunidade pesqueira do Estado da Bahia, Brasil. Actual. Biol. 22(73):195-202.

COSTA-NETO, E. M. 2000a. Restrições e preferências alimentares em comunidades de pescadores do município de Conde, Estado da Bahia, Brasil. Rev. Nutr. 13(2): 117-126, Campinas.

COSTA-NETO, E.M., ANDRADE, C.T.S., COUTO, D.F., MAGALHÃES, H.F., MASCARENHAS, L.S. \& CAMPOS, E.V.M. 2010. Diagnóstico etnoecológico em comunidades pesqueiras do município de Conde, região Litoral Norte do Estado da Bahia. In Novos olhares para o desenvolvimento regional sustentável: caminhos e perspectivas (E.M. Costa-Neto, F.M.Santos \& J.C. Londero, eds.). EDUNISC, Santa Cruz do Sul, p. 20-52.

CROFT, J.E. 1986. Relief from arthritis: the natural way. A safe and effective treatment from the ocean. Thorsons Publishing Group, Great Britain.

DIEGUES, A.C.S. 1998. Os pescadores artesanais no Brasil: uma atividade profissional e um modo de vida. In Súmula do Seminário sobre Pesca Artesanal, Conferência dos Ministros Responsáveis pela Pesca dos Países de Língua Portuguesa. MA/SDR/DPA, Salvador, p. 70-76.

DIEGUES, A.C.S \& ARRUDA, R.S.V. 2001. Saberes tradicionais e biodiversidade no Brasil. Ministério do Meio Ambiente, Brasília; Universidade de São Paulo, São Paulo.

DIELE, K., KOCH, V. \& SAINT-PAUL, U. 2005. Population structure, catch composition and CPUE of the artisanally harvested mangrove crab Ucides cordatus (Ocypodidae) in the Caeté estuary, North Brazil: Indications for overfishing? Aquat. Living Resourc. 18:169-178. http://dx.doi.org/10.1051/alr:2005018

DORIA， C.R.C., ARAÚJO, T.R., SOUZA， S.T.B. \& TORRENTE-VILARA, G. 2008. Contribuição da etnoctiologia à análise da legislação pesqueira referente ao defeso de espécies de peixes de interesse comercial no oeste da Amazônia Brasileira, rio Guaporé, Rondônia, Brasil. Biotemas 21:119-132. 
FARIAS, M.F. \& ROCHA-BARREIRA, C.A. 2007. Conchas de moluscos no artesanato cearense. Nave, Fortaleza.

FENNY, D., BERKES, F., MCCAY, B.J. \& ACHENSON, J.M. 2001. A tragédia dos comuns: vinte e dois anos depois. In Espaços naturais de uso comum (A.C.S. Diegues \& A.C.C. Moreira, orgs.). NUPAUB-USP, São Paulo, p.139-160.

FLEURY, L.C. \& ALMEIDA, J. 2007. Populações tradicionais e conservação ambiental: uma contribuição da teoria social. Rev. Bras. Agroecologia 2:3-19.

FRANCO, M.V.G. 2002. Partilhando saberes: educação ambiental na Vila de Garapuá, município de Cairú-BA. Monografia de bacharelado, Universidade Federal da Bahia, Salvador.

GARCEZ, D. S. 2007. Caracterização da pesca artesanal autônoma em distintos compartimentos fisiográficos e suas áreas de influência no estado do Rio de Janeiro. UFRJ/IGEO, Rio de Janeiro, 2007.

GHEERBRANT, A. 1993. Amazzonia, un gigante ferito. Universale Electra/Gallimard, Itália.

GLASER, M. 2003. Interrelations between mangrove ecosystem, local economy and social sustainability in Caeté Estuary, North Brazil. Wetlands Ecol. Manag. 11:265-272. http://dx.doi.org/10.1023/A:1025015600125

GLASER, M. \& DIELE, K. 2004. Asymmetric outcomes: assessing central aspects of the biological, economic and social sustainability of a mangrove crab fishery, Ucides cordatus (Ocypodidae), in North Brazil. Ecol. Econ. 49:361-373. http://dx.doi.org/10.1016/j.ecolecon.2004.01.017

GOODMAN, L.A. 1961. Amostragem bola de neve. Ann. Math. Stat. 32:148-170. http://dx.doi.org/10.1214/aoms/1177705148

GUEST, M.A., CONNOLLY, R.M., LEE, S.Y., LONERAGAN, N.R. \& BREITFUSS, M.J. 2006. Mechanism for the small-scale movement of carbon among estuarine habitats: Organic matter transfer not crab movement. Oecologia 148:88-96. PMid:16463177. http://dx.doi. org/10.1007/s00442-005-0352-5

HARDIN, G. 1968. The tragedy of the commons. Science 162:1243-1248. http://dx.doi.org/10.1126/science.162.3859.1243

HARTMANN, W.D. 1989. Conflitos de pesca em águas interiores na Amazônia e tentativas para a sua solução. In Coletânea de trabalhos apresentados do III Encontro de Ciências Sociais e o Mar. Programa de pesquisa e Conservação de Áreas Úmidas no Brasil/ IOUSP/ F. Ford/UICN, São Paulo, p. 103-118.

JANKOWSKY, M., PIRES, J.S.R. \& NORDI, N. 2006. Contribuição ao manejo participativo do caranguejo-uçá, Ucides cordatus (L., 1763), em Cananéia, SP. Bol. Inst. Pesca 32(2):221-228.

LAGES-FILHO, J. 1934. A medicina popular em Alagoas. Instituto Nina Rodrigues, Salvador.

MAGALHÃES, J. 1966. Medicina folclórica. Imprensa Universitária do Ceará, Fortaleza.

MALDONADO, S.C. 1999. A sociologia do segredo. Rev. Polít. Trab. 5:217-220

MARQUES, J.G.W. 1991. Aspectos ecológicos na etnoictiologia dos pescadores do Complexo Estuarino-Lagunar Mundaú-Manguaba, Alagoas. Tese de doutorado, Universidade Estadual de Campinas, Campinas.

MARQUES, J.G.W. 1993. Etnoecologia, educação ambiental e superação da pobreza em áreas de manguezais. In Anais do Encontro Nacional de Educação Ambiental em Áreas de Manguezais. UFBA, Maragogipe, p. 29-35.

MARQUES, J.G.W. 1995. Pescando pescadores: etnoecologia abrangente no baixo São Francisco. NUPAUB/USP, São Paulo.

MARQUES, J.G.W. 2001. Pescando pescadores: ciência e etnociência em uma perspectiva ecológica. $2^{\text {nd }}$ ed. NUPAUB/Fundação Ford, São Paulo.

MOURA, N.F.O., COELHO-FILHO, P.A. \& COELHO, P.A. 2000. Captura de Goniopsis cruentata Latreille (1803) em um manguezal do litoral norte de Pernambuco - Brasil (Crustacea, Brachyura, Grapsidae). In Anais do Mangrove 2000. UFRPE, Recife.
NASCIMENTO, D.M., MOURÃO, J.S., ROCHA, P.D., FERREIRA, E.N. \& BEZERRA, D.M.M.S.Q. 2008. Impactos sócio-ambientais provocados pela técnica "redinha" na captura do caranguejo-uçá Ucides cordatus no estuário do Rio Mamanguape (PB). In Resumos do IX Encontro de Biologia da UEFS \& IV Encontro Nordestino de Etnoecologia e Etnobiologia. UEFS, Feira de Santana.

NOMURA, H. 2001. Os crustáceos na cultura popular. Fundação Vingt-Un Rosado, Mossoró.

NORDHAUS, I., WOLFF, M. \& DIELE, K. 2006. Litter processing and population food intake of the mangrove crab Ucides cordatus in a high intertidal forest in northern Brazil. Estuar. Coast. Shelf Sci. 67:239-250. http://dx.doi.org/10.1016/j.ecss.2005.11.022

NORDI, N. 1994a. A captura do caranguejo-uçá (Ucides cordatus) durante o evento reprodutivo da espécie: o ponto de vista dos caranguejeiros. Rev. Nordest. Biol. 9(1):41-47.

NORDI, N. 1994b. A produção dos catadores de caranguejo-uçá (Ucides cordatus) na região de Várzea Nova, Paraíba, Brasil. Rev. Nordest. Biol. 9(1):71-77.

ODUM, E.P. 2001. Fundamentos de ecologia. Fundação Calouste Gulbenkian, Lisboa.

PASSOS, C.A. \& BENEDITTO, A.P.M. 2005. Captura comercial do caranguejo-uçá, Ucides cordatus (L., 1763), no Manguezal de Gargaú, RJ. Biotemas 18(1):223-231.

PISO, G. 1957. História natural e médica das Índias Ocidentais. Ministério da Educação e Cultura/Instituto Nacional do Livro, Rio de Janeiro.

POSEY, D.A. 1986. Etnobiologia: teoria e prática. In Suma Etnológica Brasileira. Etnobiologia (D. Ribeiro, org.). Vozes, Petrópolis, p.15-25.

REITERMAJER, D. 1996. Comunidade extrativista do manguezal de Porto Sauípe, Entre Rios-BA: uma abordagem ecológica e social. Monografia de bacharelado, Universidade Federal da Bahia, Salvador.

RUPPERT, E.E., FOX, S. \& BARNES, R.D. 2005. Zoologia dos invertebrados: uma abordagem funcional-evolutiva. $7^{\text {nd }}$ ed. Roca, São Paulo.

SAINT-PAUL, U. 2006. Interrelations among mangroves, the local economy and social sustainability: a review from a case study in North Brazil. In Environment and livelihoods in tropical coastal zones: managing (C.T. Hoanh, T.P. Tuong, J.W. Gowing \& B. Hardy, eds.). CABI, Wallingford, p. 154-162. http://dx.doi.org/10.1079/9781845931070.0154

SANTOS, M.C.F., BOTELHO, E.R.O. \& IVO, C.T.C. 2001. Biologia populacional e manejo da pesca de aratu Goniopsis cruentata (Latreille, 1803) (Crustacea, Decapoda, Grapsidae) no litoral sul de Pernambuco - Brasil. Bol. Tec. Cient. CEPENE 9(1):87-123.

SCHAEFFER-NOVELLI, Y. 1995. Manguezal: ecossistema entre a terra e o mar. Caribbean Ecological Research, São Paulo.

SEVERINO-RODRIGUES, E., PITA, J.B. \& GRAÇA-LOPES, R. 2001. Pesca artesanal de siris (Crustacea, Decapoda, Portunidae) na região estuarina de Santos e São Vicente (SP), Brasil. Bol. Inst. Pesca 27(1):7-19.

SOFFIATI, A. 2001. As pressões do comércio sobre a captura do gaiamum. In Resumos do III Encontro Nordestino de Educação Ambiental em Áreas de Manguezal. UFBA, Maragogipe.

SOUTO, F.J.B. 2004. A ciência que veio da lama. Uma abordagem etnoecológica abrangente das relações ser humano/ manguezal na comunidade pesqueira de Acupe, Santo Amaro-BA. Tese de doutorado, Universidade Federal de São Carlos, São Carlos.

SOUTO, F.J.B. \& MARQUES, J.G.W. 2006. “O siri labuta muito!” Uma abordagem etnoecológica abrangente da pesca de um conjunto de crustáceos no manguezal de Acupe, Santo Amaro, Bahia, Brasil. Sitientibus. Ser. Cienc. Biol. 6(Etnobiologia):106-119.

SOUZA, G.S. 2000. Tratado descritivo do Brasil em 1587: edição castigada pelo estudo e exame de muitos códices manuscritos existentes no Brasil, em Portugal, Espanha e França e acrescentada de alguns comentários por Francisco Adolfo de Varnhagen. $9^{\text {nd }}$ ed. Massagana, Recife.

SPRADLEY, J.P. \& MCCURDY, D.W. 1972. The cultural experience: ethnography in complex society. Kingsport Press of Kingsport, Tennessee.

VERGARA FILHO, W.L. \& VILLAS BOAS, M.S. 1996. Introdução ao saber dos povos da lama. In IV Encontro Nacional de Educação Ambiental em Áreas de Manguezal. Universidade Federal do Espírito Santo, Resumos, Nova Almeida, p. 22-29. 
Magalhães, H.F. et al.

WOLFF, M., KOCH, V. \& ISAAC, V. 2000. A trophic flow model of the Caeté Mangrove Estuary (North Brazil) with considerations and for the sustainable use of its resources. Estuar. Coast. Shelf Sci. 50:789-803. http://dx.doi.org/10.1006/ecss.2000.0611

WOORTMANN, E.F. 1992. O ambiente e a mulher: o caso do litoral do Rio Grande do Norte, Brasil. Lat. Am. Stud. 12:31-53.

Recebido em 21/05/2010 Versão reformulada recebida em 21/03/2011 Publicado em 20/04/2011 